\section{(6) OPEN ACCESS}

\title{
Cognitive appraisals, objectivity and coping in ambulance workers: a pilot study
}

\author{
Laura Shepherd, ${ }^{1}$ Jennifer Wild ${ }^{2,3}$
}

\begin{abstract}
- Additional supplementary files are published online only. To view these files please visit the journal online (http://dx. doi.org/10.1136/emermed2011-200511)

${ }^{1}$ Clinical Psychology and Neuropsychology Department, Nottingham University Hospitals NHS Trust, Nottingham, UK ${ }^{2}$ Department of Experimental Psychology, University of Oxford, Oxford, UK

${ }^{3}$ Department of Psychology, Institute of Psychiarty, King's College London, London, UK
\end{abstract}

\section{Correspondence to} Dr Jennifer Wild, Department of Experimental Psychology, University of Oxford, South Parks Road, Oxford OX1 3UD; jennifer.wild@psy.ox.ac.uk

Received 15 July 2011 Revised 15 July 2011 Accepted 23 November 2012 Published Online First 10 January 2013

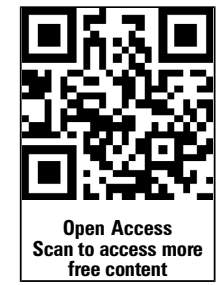

To cite: Shepherd L, Wild J. Emerg Med J 2014;31: 41-44.

\section{ABSTRACT \\ Objectives Ambulance workers are regularly exposed to call-outs, which are potentially psychologically traumatic. The ability to remain objective and make adaptive appraisals during call-outs may be beneficial to this at-risk population. This pilot study investigated the links between cognitive appraisals, objectivity and coping in ambulance workers.}

Methods Forty-five ambulance workers from the London Ambulance Service, UK, were studied. Trauma exposure, post-traumatic stress disorder and depression symptoms were assessed using self-report measures. Positive and negative appraisals were measured in relation to two previous call-outs: one during which they coped well and one during which they did not.

Results Enhanced coping was associated with making more positive appraisals during the call-out. Better coping was also related to greater levels of objectivity during these call-outs. Coping less well was associated with the use of more negative appraisals during the call-out.

Conclusions Ambulance workers may benefit from psychological interventions, which focus on cognitive reappraisal and enhancing objectivity to improve coping and resilience.

Ambulance workers regularly witness pain, distress and death and can be exposed to physical violence as well as verbal abuse during their work. Between $66 \%$ and $85 \%$ of ambulance workers report having been exposed to critical incidents at work, which they experienced as traumatic. ${ }^{1}{ }^{2}$ Studies suggest that ambulance workers may have among the highest levels of stress and burnout when compared to other groups of health professionals ${ }^{3-5}$ and to other emergency workers, including firefighters. ${ }^{3} 67$ It is a well-established finding that they are at risk of developing post-traumatic stress disorder (PTSD) and other psychological difficulties as a result of the stressful nature of their work. Prevalence rates of PTSD in ambulance workers range from $15 \%$ to $22 \%,{ }^{1}{ }^{8-10}$ and 'probable psychological distress' as measured by the general health questionnaire ${ }^{11}$ was as high as $60 \%$ in one study. ${ }^{12}$ Factors found to be associated with PTSD symptoms include organisational stress, male gender, the frequency of experiencing potentially traumatic incidents, length of service and dissociation in response to incidents. ${ }^{13}$ A lower sense of cohesion, age, number of years in the ambulance service and experiencing incidents with family members or fellow workers have also been found to be related to PTSD. ${ }^{1}$

Events involving children (particularly injured children, dead children or sexually abused children) are commonly reported as a major stressor. ${ }^{129101214}$
In addition to these, structural or organisational issues have been identified as causing stress to paramedics. These include tension with management ${ }^{3912}$ and a perceived inability to exert influence and perceived lack of control over decision-making processes. $^{7}$

Research identifying factors associated with adaptive coping in ambulance workers is important as this is linked to psychological wellbeing. The current study aimed to investigate two cognitive factors in relation to coping in ambulance workers: the use of cognitive appraisals (positive and negative) and the degree to which ambulance workers felt objective during two previous call-outs.

Many studies have reported general strategies that ambulance workers use to cope. These include using 'cognitive reframes' such as thinking that things could be worse and keeping a realistic perspective about the situation. ${ }^{4}$ Ascertaining meaning is a commonly used strategy, such as trying to understand the event, its cause and its significance. ${ }^{15}$ 'Distancing' is commonly used to cope and involves perceiving the situation in such a way that the individual feels objectively distant to it. ${ }^{12}$ Humour as a coping strategy has also been identified as helpful. ${ }^{16}$ Humour may depersonalise the event, and could lead individuals to feel objectively distant to what they have witnessed or experienced. 'Being objective' or facilitating objectivity plays a central role in reducing psychological distress. ${ }^{17}$ Reappraising negative perceptions so they are more adaptive and objective has been linked to recovery in PTSD, ${ }^{18}$ and is the main approach in cognitive therapy for depression. ${ }^{19}$ Objectivity has a long history of enquiry in philosophical disciplines and in the social sciences. In clinical psychology, being objective is most often linked to cognitivebehavioural theory and cognitive-behavioural therapy (CBT). In CBT for anxiety and depression, the aim is to promote an objective view of the self and events; an objective view is considered to be one based on evidence, unhindered by emotions. ${ }^{17}$ Some clinical psychologists hold the view that objectivity is difficult to achieve in CBT because one's values, the therapist's and the client's, influence what is perceived. ${ }^{20}$ Objectivity as defined in this study refers to taking a professionally neutral approach unhindered by strong emotions.

While the use of cognitive reframes, distancing and humour may be adaptive, making negative appraisals during or after call-outs appears to be unhelpful for coping. Making negative appraisals about intrusive memories after a call-out, for example, has been linked to the severity of PTSD in ambulance workers. ${ }^{9}$ This is unsurprising given that cognitive models of PTSD and depression used 
by psychologists emphasise the role of negative appraisals in the onset and persistence of these disorders. ${ }^{21-23}$ Modifying these through strategies such as cognitive reappraisal is linked to reductions in symptoms. ${ }^{18} 24$

Cognitive reappraisal involves changing negative appraisals into more positive ones. The aim is to change a situation's meaning to reduce its emotional impact, such as reappraising a situation as manageable instead of threatening to reduce fear. Reappraisal reduces negative emotion ${ }^{25} 26$ and physiological arousal to distressing stimuli. ${ }^{27}$ Individuals can be trained to use reappraisal, and this leads to less distress following exposure to traumatic films. ${ }^{28}$ Cognitive reappraisal is therefore an important tool in managing distress. However, it is unknown whether populations who are at risk of trauma-related distress, such as ambulance workers, may benefit from cognitive reappraisal training to enhance their coping and resilience. If enhanced coping is related to more positive reappraisals during emergency call-outs, it would suggest that cognitive reappraisal training may be beneficial for this occupational group.

While many studies have explored coping strategies used by ambulance workers, no study has yet investigated the link between cognitive appraisals or being objective, and coping in this group following specific, difficult call-outs. The hypothesis tested was that ambulance workers would have made more positive appraisals and fewer negative appraisals during a previous, difficult call-out in which they coped well compared to a difficult call-out in which they coped poorly. It was also hypothesised that enhanced coping would be associated with experiencing greater levels of objectivity during the call-out.

\section{METHODS}

\section{Design and participants}

The study was a within-subjects design. Forty-five ambulance workers (14 women) from the London Ambulance Service were recruited. The mean age of the participants was 37 years (range 26-60 years; SD 8.7 years). All but one described their ethnicity as white British. Forty per cent $(n=18)$ of the sample was graded as a paramedic and $60 \%(n=27)$ as an emergency medical technician. The mean length of time that participants had been working for the London Ambulance Service was 8.6 years (ranging from 0.8 to 30 years; SD 7.4). On average, participants had previously experienced or witnessed a mean number of nine traumatic events (ranging from two to 15 ; SD 3.3) during their working and personal lives.

\section{Measures}

Participants completed the post-traumatic stress diagnostic scale $(\mathrm{PDS})^{29}$ to measure PTSD symptoms. The PDS is a widely used measure of PTSD symptoms with 17 items. Possible scores range from 0 to 51 . Scores of 10 or less are classified as 'mild', between 11 or more and 20 or less as 'moderate', between 21 or more and 35 or less as 'moderate to severe' and 36 or more as 'severe'.

The Beck depression inventory $(\mathrm{BDI})^{17}$ was completed to measure depression. The BDI is a reliable and valid 21-item measure of depressed mood. Possible scores range from 0 to 63 . Scores of 0-9 indicate that a person is not depressed, 10-18 indicates mild to moderate depression, 19-29 indicates moderate to severe depression and scores over 30 signify severe depression.

Participants also completed a trauma screener, a modified version of the trauma list in the clinician administered PTSD scale, ${ }^{30}$ with the addition of two traumas thought to be relevant to paramedics: cot death and terrorist attacks. The trauma screener explored 19 different categories of traumatic events, including serious accidents, witnessing deaths or serious injuries, assaults, life-threatening illness, cot death and witnessing or coming across a suicide.

Finally, participants completed the responding to difficult call-outs questionnaire (see supplementary appendix 1 , available online only). This unpublished questionnaire was designed to relate to specific incidents in emergency service occupations. Participants were asked to bring to mind a previous, difficult call-out in which they perceived they coped well. They were asked to indicate how objective they had felt during the call-out (0-100\%). They then indicated whether each of 13 cognitive appraisals (seven positive and six negative) were true for them at the time of the call-out. Participants completed the same questions with reference to a difficult call-out with which they identified as coping poorly. The positive appraisals included items such as 'I imagined the event/people getting better', and 'I thought about what I could learn from the situation'. Examples of negative appraisals included 'I continually thought about how terrible it was' and 'I imagined the situation getting worse'. The internal consistency of the negative scale was acceptable (Cronbach's $\alpha=0.67$ ) as was the internal consistency of the positive scale (Cronbach's $\alpha=0.72$ ).

\section{Procedure}

Ambulance workers volunteered to participate after responding to information about the study, which had been placed in poster format at a central London ambulance station. Ambulance workers first completed the trauma screener, then the PDS, BDI and, finally, the responding to difficult call-outs questionnaire. The questionnaires were completed at the ambulance station where the participants worked.

\section{Statistical analysis}

Normality was established by inspecting histograms and QQ plots, and calculating values of skewness and kurtosis. Descriptive statistics and repeated measures $t$ tests were conducted to test the hypotheses. As the hypotheses were directional, one-tailed tests were performed. A measure of effect size (Pearson's correlation coefficient $r$ ) was also calculated to determine the importance of the effect. Consistent with standard criteria, $r=0.10$ indicates a small effect, $r=0.30$ a medium effect and $r=0.50$ a large effect. ${ }^{31}{ }^{32}$ Statistics were analysed with SPSS (V.17.0).

\section{RESULTS}

\section{PTSD and symptoms of depression}

PDS scores ranged from 0 to 28 , with a mean total score of 7.4 (SD 7.6) falling in the mild range of PTSD symptoms. Seven individuals $(15.5 \%)$ had scores greater than 18 on the PDS suggesting probable PTSD. ${ }^{33}$ The mean score on the BDI was 8.5 (SD 7.7), falling in the non-clinical range.

\section{Positive and negative appraisals}

As predicted, participants reported making more positive appraisals during call-outs with which they coped well compared to call-outs with which they coped poorly $(t=1.58$, $\mathrm{df}=44, \mathrm{p}=0.06$, one tailed). Pearson's $\mathrm{r}=0.23$, indicating a small to moderate effect. Participants reported making significantly fewer negative appraisals during call-outs with which they coped well compared to call-outs with which they coped poorly, as predicted $(\mathrm{t}=3.36, \mathrm{df}=44, \mathrm{p}=0.002$, one tailed). Pearson's $r=0.45$, indicating a moderate to large effect. 


\section{Objectivity}

The mean level of objectivity experienced during a call-out with which ambulance workers coped well was significantly higher than their level of objectivity when they coped poorly $(t=3.03$, $\mathrm{df}=43, \mathrm{p}=0.004$, one tailed). Pearson's $\mathrm{r}=0.42$, indicating a moderate to large effect.

Table 1 shows the means and SD of the number of cognitive reappraisals, negative appraisals and level of objectivity for both call-outs.

\section{DISCUSSION}

This pilot study is the first to investigate the roles of cognitive appraisals and levels of objectivity and subsequent coping in ambulance workers who have attended emergency call-outs. Fifteen per cent of the sample was above the clinical cut-off for PTSD on the self-report PTSD questionnaire, yielding a rate of PTSD in this group consistent with published studies. ${ }^{8-10}$ As predicted, ambulance workers reported making more positive appraisals and fewer negative appraisals when they attended call-outs with which they coped well compared to those in which they did not. They also reported feeling significantly more objective during these call-outs. These findings suggest a relationship between positive appraisals, objectivity and enhanced coping in ambulance staff.

Negative appraisals were related to poorer coping in this group. This is consistent with previous research of ambulance workers, which has found a relationship between negative appraisals and PTSD. ${ }^{9}$ The link between negative appraisals and poor coping is unsurprising given the established relationship between negative appraisals and the maintenance of anxiety and depression. ${ }^{21-23}$ Negative appraisals heighten negative emotion linked to the appraisal. ${ }^{25}{ }^{26}$ Second, they probably reduce the ability to focus on cues that are inconsistent with the appraisal and therefore make it less likely that reappraisal will occur. Third, they may lead the individual to develop problematical strategies such as thought suppression and rumination, which are linked to PTSD in paramedics. ${ }^{9}$

In contrast, the use of positive appraisals was linked to coping well. It is possible that positive appraisals had a positive effect on coping by reducing unpleasant emotions and perhaps increasing levels of objectivity. Cognitive reappraisal, the process of reframing a negative appraisal into a more positive one is effective in reducing psychological distress and is a technique commonly used in CBT for anxiety and depression. ${ }^{25} 26 \mathrm{It}$ appears to be similar to reframing, which has been identified as a positive coping strategy in paramedics. ${ }^{4}$

There is an alternative explanation for the findings that ambulance workers made more positive appraisals and fewer negative ones during call-outs with which they coped well and vice

Table 1 Means (and SD) of the number of positive and negative appraisals and levels of objectivity during call-outs

\begin{tabular}{lccl}
\hline & \multicolumn{2}{l}{ Traumatic call-out } & \\
\cline { 2 - 3 } Cognitive factor & $\begin{array}{l}\text { Coped well } \\
\text { Mean (SD) }\end{array}$ & $\begin{array}{l}\text { Coped poorly } \\
\text { Mean (SD) }\end{array}$ & $\begin{array}{l}\text { t Test significance } \\
\text { (one tailed) }\end{array}$ \\
\hline Positive appraisals & $3.4(2.09)$ & $2.89(1.7)$ & $\mathrm{p}=0.06$ \\
Negative appraisals & $2.04(1.38)$ & $2.8(1.29)$ & $\mathrm{p}=0.002$ \\
Objectivity* (\%) & $60.2 \%(31.1)$ & $43.2 \%(28.4)$ & $\mathrm{p}=0.004$ \\
\hline *Scored as a percentage with higher scores representing greater levels of objectivity.
\end{tabular}

versa. It may have been the perception of coping well or poorly that influenced their perception of the types of appraisals they had made during their call-outs. Prospective studies are thus needed to establish causal pathways.

It was also found that greater objectivity during difficult call-outs was related to better coping. This builds on previous research in which ambulance workers identified the strategy of keeping a realistic perspective as helpful. ${ }^{4}$ Previous research also reported that distancing helped ambulance workers cope with trauma. ${ }^{12}$ This is consistent with feeling more objective. The more ambulance workers are able to distance themselves during traumatic call-outs, the more objective they are likely to feel and the better they are likely to cope. This could be because when ambulance workers feel objective, they may believe that they are doing a better job or experience greater self-efficacy during the call-out. Future research is needed to assess the perception of job performance and self-efficacy and how these relate to coping in paramedics. It is also possible that the tendency to attribute negative events to one's self rather than the situation could influence the types of appraisals (negative or positive) one makes and coping. As such, attributional bias should also be assessed in future research.

Our study has a number of implications for ambulance workers who are a group at particular risk of developing traumatic stress due to the stressful nature of their work, the frequency of exposure to potentially traumatic incidents, their role in making decisions that could save or harm patients and organisational stressors, all of which are unique to their role in emergency work. Being able to reappraise traumatic situations cognitively is a helpful strategy whereas negatively appraising these situations with thoughts that heighten or maintain negative affect is unhelpful. ${ }^{21-27}$ Training in cognitive reappraisal may therefore be useful for this group. Recent research suggests that individuals can be trained to use cognitive reappraisal in the laboratory. ${ }^{28}$ In addition, ambulance workers may benefit from learning how to enhance levels of objectivity when attending to trauma given that this may influence their perception of coping. This may be achieved through specific adaptive appraisals, such as, 'It is helpful to remain neutral' and 'I do not need to react to this in any way other than as an objective helper'. However, further research is needed to determine the best methods to enhance objectivity.

\section{Limitations}

The current study has limitations. First, cognitive appraisals and being objective were assessed retrospectively and may therefore be subject to memory bias. A future study could assess ambulance workers immediately after attending to trauma to address this potential bias. Second, only two difficult call-outs were assessed, which limits our ability to generalise to all emergency call-outs. However, this is consistent with other studies, which have assessed the same or a lesser number of traumatic events when investigating coping strategies in this population. $^{4}{ }^{15}$ It also permitted specificity in the responses generated by participants rather than generic responses relating to a great number of emergency call-outs. Third, ambulance workers' perception of coping and unpublished measures were relied on rather than objective indices of coping, such as standardised measures or reports from supervisors or significant others. A future study could also include objective indicators of coping. Fourth, the ambulance workers were volunteers and therefore the results may not generalise to those who do not participate in research. 


\section{CONCLUSION}

This pilot study demonstrates a relationship between cognitive appraisals and objectivity in enhancing coping in ambulance workers attending to difficult call-outs. Training in cognitive reappraisal and increasing objectivity may be beneficial for individuals or occupational groups regularly exposed to trauma.

Funding This research was funded by the Wellcome Trust programme grant 069777.

Contributors Both authors planned the study. LS:collected and analysed the data and wrote the original manuscript. JW:designed and supervised the study, reviewed the data analysis, edited the original manuscript and addressed all revisions. JW is responsible for the overall content as guarantor.

\section{Competing interests None.}

Patient consent Obtained.

Ethics approval The study was approved by the Lewisham Research Ethics Committee (REC ref. 07/Q0701/29) and the London Ambulance Service Clinical Audit and Research Unit (LAS R\&D ref. LAS/EXT/2007/03).

Provenance and peer review Not commissioned; externally peer reviewed.

Open Access This is an Open Access article distributed in accordance with the Creative Commons Attribution Non Commercial (CC BY-NC 3.0) license, which permits others to distribute, remix, adapt, build upon this work non-commercially, and license their derivative works on different terms, provided the original work is properly cited and the use is non-commercial. See: http://creativecommons.org/ licenses/by-nc/3.0/

\section{REFERENCES}

1 Jonsson A, Segesten K, Mattsson B. Post-traumatic stress among Swedish ambulance personnel. Emerg Med J 2003;20:79-84.

2 van der Ploeg E, Kleber RJ. Acute and chronic job stressors among ambulance personnel: predictors of health symptoms. Occup Environ Med 2003 Jun;60 Suppl $1: i 40-6$

3 Boudreaux E, Mandry C, Brantley PJ. Stress, job satisfaction, coping, and psychological distress among emergency medical technicians. Prehosp Dis Med 1997; 12:242-9.

4 Durham TW, McCammon SL, Allison EJ. The psychological impact of disaster on rescue personnel. Ann Emerg Med 1985;14:664-8.

5 Hammer JS, Mathews JJ, Lyons JS, et al. Occupational stress within the paramedic profession: an initial report of stress levels compared to hospital employees. Ann Emerg Med 1986;15:536-9.

6 Marmar CR, Weiss DS, Metzler TJ, et al. Stress responses of emergency services personnel to the Loma Prieta earthquake interstate 880 freeway collapse and control traumatic incidents. J Trauma Stress 1996;9:63-85.

7 Young KM, Cooper CL. Occupational stress in the ambulance service: a diagnostic study. J Mgl Psychol 1995;10:29-36.

8 Bennett $P$, Williams $Y$, Page $N$, et al. Levels of mental health problems among UK emergency ambulance workers. Emerg Med J 2004;21:235-6.

9 Clohessy S, Ehlers A. PTSD symptoms, responses to intrusive memories and coping in ambulance service workers. Br J Clin Psychol 1999;38:251-65.
10 Rentoul R, Ravenscroft T. Managing post traumatic stress in the emergency services. Disaster Manag 1993;5:199-201.

11 Goldberg DP, Hillier VF. A scaled version of the General Health Questionnaire. Psychol Med 1979;9:139-45.

12 Thompson J, Suzuki I. Stress in ambulance workers. Disaster Manag 1991;3:193-7.

13 Bennett $P$, Williams $Y$, Page $N$, et al. Associations between organizational and incident factors and emotional distress in emergency ambulance personnel. $\mathrm{Br}$ J Clin Psychol 2005;44:215-26.

14 Alexander DA, Klein S. Ambulance personnel and critical incidents: impact of accident and emergency work on mental health and emotional well-being. $\mathrm{Br} \mathrm{J}$ Psychiatry 2001;178:76-81

15 McCammon S, Durham TW, Allison EJ, et al. Emergency workers cognitive appraisal and coping with traumatic events. J Trauma Stress 1988:1:353-72.

16 Rosenberg L. A qualitative investigation of the use of humour by emergency personnel as a strategy for coping with stress. J Emerg Nurs 1991;17:197-203.

17 Beck AT, Rush AJ, Shaw BF, et al. Cognitive therapy of depression. New York: Guilford, 1979.

18 Bryant RA, Moulds ML, Guthrie RM, et al. Imaginal exposure alone and imaginal exposure with cognitive restructuring in the treatment of posttraumatic stress disorder. J Consult Clin Psychol 2003;71:706-12.

19 Butler AC, Beck AT. Cognitive therapy for depression. Clin Psychol 1995;18:3-5.

20 Proctor G. CBT: collaboration or compliance. Clin Psychol 2003;25:14-16.

21 Ehlers A, Clark DM. A cognitive model of posttraumatic stress disorder. Behav Res Ther 2000;38:319-45.

22 Beck AT. Depression: clinical, experimental and theoretical aspects. New York: Harper and Row, 1967.

23 Beck AT. Cognitive therapy and the emotional disorders. New York: International Universities Press, 1976.

24 Ehlers A, Clark DM, Hackmann A, et al. Cognitive therapy for post-traumatic stress disorder: development and evaluation. Behav Res Ther 2005;43:413-31

25 Gross JJ. The emerging field of emotion regulation: an integrative review. Rev Gen Psychol 1998;2:271-99.

26 Gross JJ. Emotion regulation: affective, cognitive and social consequences. Psychophysiology 2002;39:281-91.

27 Hofmann SG, Heering S, Sawyer AT, et al. How to handle anxiety: the effects of reappraisal, acceptance, and suppression strategies on anxious arousal. Behav Res Ther 2009;47:389-94.

28 Schartau PES, Dalgleish T, Dunn BD. Seeing the bigger picture: training in perspective broadening reduces self-reported affect and psycho-physiological response to distressing films and autobiographical memories. J Abnorm Psychol 2009;118:15-27

29 Foa EB, Cashman L, Jaycox L, et al. The validation of a self-report measure of posttraumatic stress disorder: the posttraumatic stress diagnostic scale. Psychol Assess 1997;9:445-51.

30 Blake DD, Weathers FW, Nagy, et al. The development of a clinician-administered PTSD scale. J Trauma Stress 1990;8:75-90.

31 Cohen J. Statistical power analysis for the behavioural sciences, 2nd edn. New York: Academic Press, 1988.

32 Cohen J. A power primer. Psychol Bull 1992;112:155-9.

33 Ehring T, Kleim B, Clark DM, et al. Screening for posttraumatic stress disorder: what combination of symptoms predicts best? J Nerv Ment Dis 2007;195:1004-12. 